\title{
Serebral Venöz Trombozda Trombosit Aktivasyonu ile Rekanalizasyon Süresi İlişkisi
}

\author{
Mustafa Ceylan $^{1 *}$, Fatma Şimşek $^{1}$ \\ ${ }^{1}$ Atatürk Üniversitesi Tıp Fakültesi, Nöroloji Anabilim Dalı, Erzurum, Türkiye \\ drmuson16@hotmail.com,klamaks@hotmail.com \\ Orcid: 0000-0002-9916-0156 \\ Orcid: 0000-0003-1662-5534 \\ *Sorumlu Yazar / Corresponding Author: Mustafa Ceylan \\ Gönderim Tarihi / Received:22.10.2018 \\ Kabul Tarihi / Accepted: 19.06.2019 \\ DOI: $10.34087 /$ cbusbed.486839
}

\begin{abstract}
$\ddot{\mathbf{O} z}$
Amaç: Serebral venöz tromboz nadir görülen bir inme nedenidir. Tedavide antikoagülan ajanlar kullanılmaktadır. Tedavide amaç trombozu ortadan kaldırarak rekanalizasyonu sağlamaktır. Rekanalizasyon süresi sıklıkla 3-12 ay arasında değişmektedir. Trombositlerin tromboz oluşumunda önemli rolü vardır. Ortalama trombosit hacmi (OTH) ve trombosit dağılım genişliği (TDG) trombosit aktivasyonunu gösteren parametrelerdir. Biz çalışmamızda rekanalizasyon süresi üzerine etki eden faktörleri, OTH ve TDG ile rekanalizasyon süresi arasında bir ilişki olup olmadığını belirlemeyi amaçladık.
\end{abstract}

Gereç ve Yöntemler: Çalışmamız retrospektif olup serebral venöz tromboz tanısı ile takipli ve takipte rekanalizasyon izlenen 37 hastayı kapsamaktadır.

Bulgular: Çalışmaya Ocak 2012-Haziran 2018 tarihleri arasında serebral venöz tromboz tanısı ile takip edilip rekanalizasyon izlenen 6'sı erkek, 31'i kadın 37 hasta ve yaş, cinsiyet eşleşmeli sağlıklı bireyler alındı. OTH ve TDG değerleri SVT grubunda anlamlı olarak daha yüksekti, ortalama rekanalizasyon süresi 7.7 aydı. Yaş, cinsiyet, etyoloji, parankim hasarı, tutulan sinüs ve tutulan sinüs sayısı rekanalizasyon süresi üzerine etkili değildi. Süperior sagital sinüs tutulumu ile rekanalizasyon süresi arasında anlamlı istatistiksel ilişki tespit edildi.

Sonuç: Tespitlerimizin çoğu literatür ile farklıydı, bu durum metodolojik farklılıktan kaynaklanabileceği gibi rekanalizasyonun birçok faktör tarafından aynı anda etkilenebileceğini ve olguya göre değişebileceğini akla getirmektedir. Ayrıca OTH ve TDG' nin rekanalizasyon süresinin tahmininde biyobelirteç olarak kullanımı uygun değildir.

Anahtar Kelimeler: Ortalama Trombosit Hacmi, Trombosit Dağılım Genişliği, Serebral Venöz Tromboz, Reanalizasyon Zamanı.

\footnotetext{
Abstract

Objective: Cerebral venous thrombosis is a rare cause of stroke. Treatment consists of anticoagulant agents. Aim of treatment is to remove the clot and maintain the recanalization. Duration of recanalization often lasts between 3 and 12 months. Thrombocytes have an important role in thrombosis. Mean thrombocyte volume (MTV) and thrombocyte distribution width (TDW) are the parameters associated with thrombocyte activation. In this study, we investigated the possible factors that affect the recanalization duration and assessed link between recanalization and the MTV and TDW.

Material and Method: Between January 2012 and June 2018 Our retrospective study includes 37 patients (6 male, 31 female) who had the diagnosis of cerebral venous thrombosis followed by recanalization. Control group consisted of age and gender matched healthy individuals.

Results: MTV and TDW were higher in thrombosis group. Mean recanalization duration was 7.7 months. Age, gender, etiology, presence of parenchymal injury, and number of affected sinus were not associated with recanalization duration. Superior sagittal sinus involvement was, statistically, found to be associated with recanalization duration.

Conclusions: Most of our findings differed from the literature. This suggests the methodological differences of our study. We also think that diverse results could be due to affected recanalization process by many factors at the same
} 
time and individual differences. We found that MTV and TDW cannot be used as biomarkers in the prediction of duration of recanalization.

Keywords: Mean Thrombocyte Volume, Thrombocyte Distribution Width, Cerebral Venous Thrombosis, Recanalization Duration.

\section{Giris}

Serebral ven trombozu (SVT), iskemik inmenin nadir görülen nedenlerinden biridir. İnsidansı yılda 0.2 1.2/100.000 olgudur [1]. Her yaş grubunda görülmekle birlikte en çok genç yetişkinleri, doğurganlık çağındaki kadınları ve çocukları etkilemektedir. Kadınlar, erkeklerden daha fazla etkilenmektedir [2]. SVT kliniği çeşitli semptomlardan oluşur $[3,4]$. Fakat en sık izlenen semptomun baş ağrısı olduğu bildirilmiştir [5]. Günümüzde serebral yapıların ve venöz trombozun tanısı için altın standart kranyal manyetik resonans görüntülemedir (MRG). Kontrastsız venöz MRG anjiografi venöz yapıdaki trombüs oluşumunu gösterir [6], fakat kontrastlı tekniklerin daha hassas olduğu düşünülmektedir [7]. Venöz MR anjiografi hastalığın takibinde, rekanalizasyonu değerlendirmek için uygun bir tekniktir [8]. SVT' nin standart tedavisi, intrakranial kanama varlığında dahi sistemik antikoagülasyondur [9]. Tedavide amaç klinik düzelme ve rekanalizasyon sağlamaktır. Amerikan İnme Derneği yeterli antikoagülan tedaviye rağmen hastaların \%9-13' ünde yetersiz rekanalizasyon ve/veya kalıcı tromboz nedeniyle klinik kötüleşme görülebileceğini bildirmiştir [10]. Amerika ve Avrupa kılavuzları antikoagülan tedaviye rağmen klinik bozulma devam ederse endovasküler tedavi uygulanmasını önermektedir $[9,10]$. Cinsiyet, yaş, etyoloji, malignite varlığı gibi birçok faktörün rekanalizasyon üzerine etkili olduğu bildirilmiştir [11,12]. Rekanalizasyon üzerine yapılmış çok az çalışma vardır [13-15]. SVT' de ilk aylarda gerçekleşen rekanalizasyonun antikoagülan tedaviyle ilişskili olmadığı, tedaviden bağımsız gerçekleştiği bildirilmiştir [16]. Tam rekanalizasyonun ortalama 6 ayda olduğu bildirilmiştir [8].

Şuana kadar rekanalizasyon ile ilgili çalışmalarda klinik, demografik özellikler ve görüntülemede tespit edilen hasar ve trombüs lokalizasyonu ile ilişkisi haricinde trombozun oluşumunda temel fonksiyonlarının olduğu bilinen trombositlerin ortalama hacimleri $(\mathrm{OTH})$ ve dağılım genişliklerinin kullanıldığ (TDG) bir çalışma yoktur. OTH ve TDG trombosit aktivasyonunu gösteren belirteçlerdir [17,18]. Bazı çalışmalar akut miyokard infarktüsü, iskemik inme gibi bazı arteryel iskemik hastalıklarda OTH yüksekliğinin kötü sonuçla ilişkili olduğunu bildirmiştir [19,20]. Henüz tam olarak anlaşılamamış olsada venöz tromboz ve arteriyel tromboz gelişim süreçlerinin farklı olduğu bildirilmiştir [21], fakat arteryel inme ve venöz trombozlarda benzer sonuçlar bildirilmiştir [22,23].

Literatürde rekanalizasyon süresi üzerine etkili faktörlerin araştırıldığı bir çalışma bildirilmemiştir. Rekanalizasyona etkili faktörlerin incelendiği çalışmalarda tam veya kısmi rekanalizasyon sağlanan hastalarda yada hiç rekanalizasyon sağlanmayan hastalarda etkili faktörler incelenmiştir. Bu çalışmanın amacı tam rekanalizasyon sağlanan SVT' li olgularda hastalık özellikleri, ortalama trombosit hacmi ve trombosit dağılım genişliği ile rekanalizasyon süresi arasında bir ilişki olup olmadığını araştırmaktır.

\section{Gerec ve Yöntem}

Bu çalışmada 2012 Ocak-2018 Haziran ayları arasında nöroloji kliniğinde SVT tanısı ile takip edilen 55 hastanın dosyası retrospektif olarak incelendi. Takip manyetik rezonans (MR) venografi görüntüleri hastane bilgi yönetim sisteminde olan hastaların tetkikleri yeniden değerlendirildi, MR venografisinde rekanalizasyon izlenen 37 hasta çalışmaya dahil edildi. 18 hasta enfeksiyon, iskemik inme, hematolojik hastalık, onkolojik hastalık, periferik vasküler hastalık, akut miyokard enfarktüsü, konjestif kalp yetmezliği, kronik karaciğer hastalığı öyküsü olanlar ve tanı öncesi belirlenen ilaçlardan (antiagregan, antikoagülan, antihiperlipidemik ve psikotrop) bir veya birkaçının kullanımı nedenleri ile ve MR venografisinde henüz rekanalizasyon izlenmeyen hastalar çalışma dişı bırakıldı. Hastalarda etyoloji, parankim hasarı, tutulan sinüs sayısı (bir veya birden fazla) ve rekanalizasyon sağlanana kadar geçen süre ay olarak kayıt edildi. Kontrol grubu sağlık durum bildirir raporu alıp, herhangi bir hastalığı olmayan olgular arasından yaşcinsiyet eşleşmeli olacak şekilde oluşturuldu. Hastaların SVT tanısı konulduğu dönemdeki ortalama trombosit hacmi $(\mathrm{OTH})$ ve trombosit dağılım genişliğine (TDG) hastane bilgi yönetim sisteminden ulaşıldı. Merkezimizde tüm hastalara ilk antikoagülasyon vücut ağırlığına göre ayarlanmış düşük moleküler ağırlıklı heparin (DMAH) ile başlatılır ve daha sonrada DMAH veya oral antikoagülasyon (Warfarin) tedavilerinden biri ile devam edilir.

Çalışma kurumsal etik kurulumuz tarafindan onaylanmıştır (06/22/04.10.2018).

\subsection{MRG protokolü}

SVT tanısıyla takip edilmiş, aksiyel FLAIR, aksiyel T1, aksiyel T2, koronal T2, sagittal T1 ve time of flight (TOF) venografi ve kontrastlı venografi görüntüler ile trombüs tespit edilmiş ve takibinde aynı teknikle yapılmış görüntülemede rekanalizasyon izlenmiş hastalar çalışmaya dahil edildi.

\section{2. İstatistiksel Analiz}

Verilerin normal dağılıma uyup uymadığı D'AgostinoPearson testi ile kontrol edildi. Nominal veriler ki-kare testi kullanılarak karşılaştırıldı. Normal dağılıma uyan iki grup arasındaki karşılaştırma bağımsız $\mathrm{t}$ testi ile; ikiden fazla sayıdaki grup arasındaki karşılaştırma ANOVA testi kullanılarak yapıldı. Sıralı değişkenler arasındaki korelasyon Spearman korelasyonu ile araştırılırken, numerik değişkenler 
arasındaki korelasyon Pearson korelasyonu ile araştırıld1. İki yönlü $\mathrm{p}$ değeri $<0,05$ 'ten küçük hesaplamalar anlamlı olarak kabul edildi. Tüm istatistiksel hesaplamalar Medcalc (Medcalc, ver.12, Ostend, Belçika) program kullanılarak yapıldı.

\section{Bulgular ve Tartışma}

Ocak 2012-Haziran 2018tarihleri arasında SVT tanısı ile takip edilen 37 hasta ve yaş cinsiyet eşleşmeli sağlıklı kontrollerin verileri incelendi. 37 hastanın 31' i (\%83.8) kadındı. Hastaların yaşları 21-72 arasında değişmekte olup, yaş ortalaması $38.1( \pm 12.2)$ olarak tespit edildi. Hasta grubu ile kontrol grubu arasında OTH ve TDG değerleri arasında anlamlı istatistiksel fark tespit edildi (Tablo-1).

Tablo1.Hastavekontrolgrubuarasındakidemografikv eçalışmaverilerininkarşılaştırılması.

\begin{tabular}{|c|c|c|c|}
\hline & SVT & Kontrol & p değeri \\
\hline Yaş.yıl (ortalama \pm SS) & \multicolumn{2}{|c|}{$38.1 \pm 12.2$} & \\
\hline $\begin{array}{l}\text { Cinsiyet }(\%) \\
\text { Erkek } \\
\text { Kadın } \\
\end{array}$ & \multicolumn{2}{|c|}{\begin{tabular}{|c|}
$6(16.2)$ \\
$31(83.8)$ \\
\end{tabular}} & \\
\hline OTH. fL(ortalama \pm SS) & $10.4 \pm 1.4$ & $8.8 \pm 1.5$ & 0.001 \\
\hline TDG. (ortalama \pm SS) & $14.9 \pm 2.9$ & $11.1 \pm 2.1$ & $<0.001$ \\
\hline \multicolumn{4}{|c|}{$\begin{array}{l}\text { OTH: Ortalama trombosit hacmi. TDG: Trombosit } \\
\text { dağılım genişliği }\end{array}$} \\
\hline
\end{tabular}

Hastaların etiyolojik nedenleri incelendiğinde en s1k $(\% 32,4)$ idiyopatik olduğu tespit edildi. Hasta grubumuzda en sik tutulan sinüs $\% 78,4$ ile süperior sagital sinüs, en sık klinik bulgu \%89,1 ile baş ağrısıydı (Tablo-2).

Parankim hasarı ve tutulan sinüs sayısı ile OTH ve TDG değerleri arasında ilişki yoktu (p:0,671, p:0,584). Rekanalizasyon sağlandıktan sonra herhangi bir engellilik veya klinik semptom yoktu. Rekanalizasyon süreleri hastalar arasında 3-36 ay arasında değişmekteydi ve ortalama rekanalizasyon süresi 7.7 $( \pm 5.9)$ ay olarak tespit edildi. Yaş, cinsiyet, etyoloji, parankimal hasar varlığı, tutulan sinus sayısı, OTH ve TDG değerleri ile rekanalizasyon süresi arasındaki ilişki incelendi. Yaş, OTH, TDG oranları ve tutulan sinus sayısı ile rekanalizasyon süresi arasında anlamlı korelasyon tespit edilmedi (p:0,519, p:0,955, p:0,567, $\mathrm{p}: 0,179)$. Yine cinsiyet, etyoloji ve parankim hasarı varlığı ile rekanalizasyon süresi arasında anlamlı ilişki tespit edilmedi (p:0,687, p:0,425, p:0,121). Rekanalizasyon süresi ile tutulan sinüs arasında ilişki incelendiğinde, süperior sagital sinüs tutulumunun rekanalizasyon süresi ile ilişkili olduğu tespit edildi (p:0,038).

\begin{tabular}{|c|c|c|}
\hline & $\mathbf{n}$ & $\%$ \\
\hline \multicolumn{3}{|l|}{ Etiyolojik nedenler } \\
\hline Gebelik/postpartum dönem & 10 & 27 \\
\hline Oral kontraseptif kullanımı & 6 & 16.2 \\
\hline Vaskülit & 5 & 13.5 \\
\hline İdiyopatik & 12 & 32.4 \\
\hline Hiperkoagübilite & 4 & 10.8 \\
\hline \multicolumn{3}{|l|}{ Tutulan sinüsler } \\
\hline Superior Sagittal Sinüs & 29 & 78.4 \\
\hline Transvers Sinüs & 21 & 56.7 \\
\hline Sigmoid Sinüs & 11 & 29.7 \\
\hline Kavernöz Sinüs & 1 & 2.7 \\
\hline Serebral Derin Venler & 1 & 2.7 \\
\hline Jugular Ven & 5 & 12.4 \\
\hline \multicolumn{3}{|l|}{ Klinik bulgular } \\
\hline Baş ağrisı & 33 & 89.1 \\
\hline Epileptik nöbet & 6 & 16.2 \\
\hline Papilödem & 7 & 18.9 \\
\hline Çift görme & 4 & 10.8 \\
\hline Bilinç değişikliği & 2 & 5.4 \\
\hline Hemiparezi/hemihipoestezi & 4 & 10.8 \\
\hline \multicolumn{3}{|l|}{ Parankim Hasarı } \\
\hline Var & 13 & 35.1 \\
\hline Yok & 24 & 64.9 \\
\hline \multicolumn{3}{|l|}{ Tutulan Sinüs Sayısı } \\
\hline Tek Sinüs Tutulumu & 12 & 32.4 \\
\hline Çoklu Sinüs Tutulum & 25 & 67.6 \\
\hline
\end{tabular}

Tablo 2. Hastalarda etiyolojik nedenler, tutulan sinüsler, parankim hasarı, klinik bulgular

\section{Tartışma}

Çalışmamızda OTH ve TDG değerleri SVT grubunda anlamlı olarak daha yüksekti, ortalama rekanalizasyon süresi 7,7 aydı. Yaş, cinsiyet, etyoloji, parankim hasarı, tutulan sinüs sayısı rekanalizasyon süresi üzerine etkili değildi, fakat süperior sagital sinüs tutulumu rekanalizasyon süresine etkiliydi.

SVT 20-40 yaş aralığında daha sıktır [24]. Kadınlarda 3,7-5,3 kat daha fazla görüldüğü bildirilmiştir [25]. SVT nedenleri karmaşıktır, yaygın nedenler arasında tümör, travma, enfeksiyon, gebelik ve puerperium, trombofili, sistemik hastalıklar, oral kontraseptifler, metabolik bozukluklar, dehidratasyon, vs. vardır, fakat hala SVT' nin $\% 30^{\prime}$ unda belirgin bir neden bulunamadığ bildirilmiştir [26]. Çalışmamızda hasta grubunun yaş ortalamasını $38.1( \pm 12,2)$ tespit ettik ve kadın hasta oranımız yaklaşık 5 kat daha fazlaydı (31 kadın, 6 erkek), tespitlerimiz literatür ile uyumluydu. Hastaların $\% 32,4^{\prime}$ u idiyopatik gruptayd 1 ve ikinci sıklıkta gebelik ve ve postpartum dönemle (\%27) ilişkiliydi. SVT' de ensık görülen semptom baş ağrısıdır ve hastaların \%8090' inda gözlenir [27]. SVT' de en s1k tromboz tespit edilen bölgelerin superior sagittal sinüs $\% 65$, transvers sinüs $\% 60,5$ ve $\% 71,2$ olguda çoklu venöz tromboz olduğu bildirilmiştir [4]. Çalışmamızda en sık semptom baş ağrısıydı $(\% 89,1)$ ve superior sagittal sinüsün 
\%78.4, transvers sinüsün \%56.7 tutulduğunu tespit ettik. Tespitlerimiz literatür verileri ile uyumluydu.

SVT etyolojisinde merkezi sinir sistemi enfeksiyonu, herhangi bir malign hastalık olması, kabul nörogörüntülemesinde intrakraniyal kanama, bilinç bozukluğu ve Glasgow Koma Skalası <9 olması, 37 yaşından büyük ve erkek cinsiyetin kötü prognozla ilişkili olabileceği bildirilmiştir [28]. Kafa içi basınç artışı, bilinç kaybı, parankim hasarı, nörolojik defisit hastalarda görülebilecek komplikasyonlardır [29]. Erken dönemde tanı konulup tedavi başlanarak rekanalizasyon sağlanması komplikasyon gelişim riskini azaltacaktır. Çok az sayıda çalışma SVT sonrası rekanalizasyon oranlarını araştırmıştır [12-14]. 3 ila 6 ay arasında, tam rekanalizasyon oranları \% 51-57, kısmi rekanalizasyon oranları \% $19-45$ gibi bildirilmiştir [14,30]. Antikoagülan tedavi altında rekanalizasyon zamanı üzerine etkili faktörlerin incelendiği, 12 ay takipli prospektif bir çalışmada rekanalizasyon oranlarının zamanla arttığı, 3 . ayda $\% 32.4,12$. ayda $\% 72.9^{\prime}$ a çıtı̆̆ı tespit edilmiş, ayrıca 50 yaş altı ve süperior sagital sinüs trombozu varlığı erken rekanalizasyon için öngörücü olabileceği bildirilmiştir [11]. 6 aylık takibin yer aldığı bir çalışmada hastaların \%47' sinde tam rekanalizasyon sağlandığı bildirilmiştir, aynı çalışmada 37 yaş üstü hastalarda, erkek cinsiyette ve idiyopatik etyolojili SVT' lerde tam rekanalizasyonun olumsuz etiklendiği tespit edilmiştir [12]. Aynı çalışmada parankim hasarı varlığı ve tutulan sinüs sayısının rekanalizasyon üzerine etikisinin olmadığı bildirilmiştir [12]. Farklı bir çalışmada tam rekanalizasyon sağlanan hastalarda bu sürenin ortalama 6 ay olduğu tespit edilmiştir [8].

Rekanalizasyonun sıklıkla 3-6 ayda geliştiği ve nadirende olsa 12 . ayda veya daha uzun sürede gelişebildiği bildirilmiştir. Aynı çalışmada rekanalizasyon üzerine etkili faktörler incelendiğinde cinsiyet, yaş, tutulan sinüs sayısı ve parankim hasarı ile ilişkili olmadığı fakat hormon tedavisi ile gelişen SVT ile ilişkili olduğu yine, süperior sagital sinüs tutulumunun rekanalizasyon gelişmesi üzerine pozitif etkili olduğu bildirilmiştir [8]. Daha yeni bir çalışmada etyoloji, parankim hasarı, tedavi yaklaşımının rekanalizasyon üzerine etkisinin olmadığı ve rekanalizasyonun klinik sonuca etkisinin olmadığı bildirilmiştir [31]. Yine farklı çalışmalarda rekanalizasyon ve klinik sonuç arasında ilişki gösterilmemişken [30,32] rekanalizasyon ve iyi klinik sonuç arasında anlamlı bir ilişki olduğunu bildiren çalışmalarda vardır [33]. Çalışmamızda rekanalizasyon süreleri hastalar arasında 3-36 ay arasinda değişmekteydi ve ortalama rekanalizasyon süresi $7.7( \pm 5.9)$ ay olarak tespit edildi. Yaş, cinsiyet, etyoloji, parankimal hasar varlığı ve tutulan sinus sayısı ile rekanalizasyon süresi arasındaki ilişki incelendi. Bahsedilen parametrelerden hiç biri rekanalizasyon süresi üzerine etkili değildi. Tespitlerimizden sadece rekanalizasyon süresinin süperior sagital sinüs tutulumu ile ilişkili olması, süperior sagital sinüs tutulumunun rekanalizasyon gelişmesinde öngörücü olduğu bildirilen çalışmalar ile uyumluydu. Çalışmamızın metodolojisi rekanalizasyon üzerine etkili parametreleri araştıran çalışmalarınkinden farklıydı, bu çalışmalarda gruplar tam, kısmi rekanalizasyon ve hiç rekanalizasyon olmayan gruplardan oluşmaktaydı, çalışmamız ise tam rekanalizasyon olan gruptan oluşmaktayd. Sonuçlarımızın farklı olması metodolojik farklılıktan kaynaklanabileceği gibi rekanalizasyonun bağımsız tek bir faktörle ilişkili olmadığı, birçok faktör tarafından aynı anda etkilenebileceği (cinsiyet, yaş, etyolojik neden, doğal antikoagülan sistemin aktivitesi) ve olguya göre değişebileceğini akla getirmektedir. Ayrıca tam rekanalizasyon sağlanmış hastaların hiç birisinde nörolojik semptom kalmamıştı, yani rekanalizasyonun klinik sonuçla ilişkili olduğunu düşündürmektedir.

Trombozun patogenezi halen virchow triadı ile açıklanmaktadır [34]. Bu triad kan akımı ve damar duvarı değişiklikleri ile koagülasyon bozukluklarından oluşmaktadır [34]. Venöz trombüsler fibrin, trombosit, az sayıda lökosit ve üzerine eklenen eritrosit kümelerinden oluşur. Trombositler aterosklerotik komplikasyonların patogenezinde ve trombüs oluşumunda önemli bir role sahiptir. OTH ve TDG, trombosit aktivasyonunu göstermektedir [17,18]. Trombosit büyüklüğü, trombosit agregasyonu, tromboksan A2, trombosit faktör 4 ve tromboglobulin salınımı OTH ile ölçülür [17]. Büyük trombositler küçük trombositlerden daha fazla granüller içermektedir, enzimatik ve metabolik olarak daha aktif olmaları nedeniyle daha fazla trombotik potansiyele sahiptirler. Büyük trombositlerde tromboksan A2 gibi protrombotik bileşenler daha fazladır [35]. OTH arttığ1 durumlarda trombosit sayıları düşme eğilimindedir [36]. OTH ve TDG' nin birlikte değerlendirilmesi koagülasyon aktivasyonunu göstermede daha etkindir [37]. Arteryel iskemide OTH artışının kötü prognostik faktör olduğunu bildiren çalışmalar varken [19,20], benzer sonuçlar venöz olaylar içinde geçerlidir [22,23]. Yapılan bir çalışmada OTH ve TDG değerleri SVT grubunda sağlıklı kontrollerden yüksek tespit edilmişken, SVT' liler arasında parankim hasarı varlı̆̆ ile ilişki tespit edilmemiştir [38]. Farklı bir çalışmada OTH ve TDG oranlarının SVT' lerde anlamlı olarak daha yüksek olduğu, fakat parankim hasarı ve prognoz ile ilişkisi olmadığı bildirilmiştir [31]. Çalışmamızda SVT grubunda OTH ve TDG değerleri sağlıklı kontrol grubuna göre anlamlı olarak daha yüksekti, fakat parankim hasarı ve tutulan sinüs sayısı ile OTH ve TDG değerleri arasında ilişki tespit edilmedi. Tespitlerimiz bu yönüyle literatürü desteklemekteydi. Rekanalizasyon süresi ile OTH ve TDG değerleri arasında anlamlı ilişki tespit edilmedi. Tespitimiz rekanalizasyon üzerine etkili birçok faktör olduğunu desteklemektedir.

Çalışmamızda hasta popülasyonunun az olması kısıtlayıcı tarafıdır, sonuçlarımızın güvenilirliğini azaltmaktadir. 


\section{Sonuç}

Günümüz şartlarında $\mathrm{MRG}^{\prime}$ ye rahat ulaşılabilsede, artan hayatta kalım süresi, nüfus yoğunluğu ve farklı birçok tıbbi durumun tanı ve takibinde MRG kullanıldığı düşünüldüğünde, görüntüleme sayısını azaltmak, takip süresi ve prognoz hakkında yorum yapabilmek için rekanalizasyon süresini tahmin edebilecek bir biyo-belirtecin kullanımı fonksiyonel olacaktır. Şuana kadar rekanalizasyon süresini tahmin edebilecek herhangi bir biyokimyasal parametre çalışılmamıştır. Tromboz oluşumu ile ilişkili biyokimyasal belirteçler ile tahmin yürütebilmek, patofizyoloji düşünüldüğünde uygun görülsede çalışmamız bu görüşü desteklememektedir.

\section{Referanslar}

1. Coutinho, JM, Zuurbier, SM, Aramideh, M, Stam, J. The incidence of cerebral venous thrombosis: a cross-sectional study. Stroke 2012;43:3375-3377.

2. deVeber, G, Andrew M, Adams C, Bjornson B, Booth F, Buckley, DJ, Camfield CS, David M, Humphreys $\mathrm{P}$, Langevin P, MacDonald EA, Gillett J, Meaney B, Shevell M, Sinclair DB, Yager J; Canadian Pediatric Ischemic Stroke Study Group. Cerebral sinovenous thrombosis in children. N Engl J Med 2001;345:417-423.

3. Sparaco, M., Feleppa, M., Bigal, M. E. Cerebral venous thrombosis and headache-a case-series. Headache 2015;55:806-814.

4. Sassi, S. B.,Touati N., Baccouche H., Drissi C., Romdhane N. B., Hentati F. Cerebral venous thrombosis: a tunisian monocenter study on 160 patients. Clin. Appl. Thromb. Hemost. 2016; 23:1005-1009.

5. Agostoni E. Headache in cerebral venous thrombosis. Neurol. Sci. 2004;25:206-10.

6. Bousser, MG. Cerebral venous thrombosis: diagnosis and management. J Neurol 2000;247: 252-8.

7. Lettau, M, Laible M, Barrows RJ, Heiland S, Bendszus M, Hahnel S. 3-T contrast-enhanced MR angiography with parallel imaging in cerebral venous and sinus thrombosis. $\mathbf{J}$ Neuroradiol 2011;38:275-2.

8. Herweh C, Griebe M, Geisbüsch C, Szabo K, NeumaierProbst E, Hennerici MG, Bendszus M, Ringleb PA, Nagel S. Frequency and temporal profile of recanalization after cerebral vein and sinus thrombosis. Eur J Neurol. 2016;23:681-7.

9. Einhaupl K, Stam J, Bousser MG, De Bruijn SF, Ferro JM Martinelli I, Masuhr F; European Federation of Neurological S EFNS guideline on the treatment of cerebral venous and sinus thrombosis in adult patients. Eur $\mathbf{J}$ Neurol. 2010;17:1229-35.

10. Saposnik G, Barinagarrementeria F, Brown RD Jr, Bushnell CD, Cucchiara B, Cushman M, deVeber G, Ferro JM, Tsai FY. Diagnosis and management of cerebral venous thrombosis: a statement for healthcare professionals from the American Heart Association/American Stroke Association. Stroke. 2011;42:1158-92.

11. Arauz A, Vargas-González JC, Arguelles-Morales N, Barboza MA, Calleja J, Martínez-Jurado E, Ruiz-Franco A, QuirozCompean A, Merino JG. Time to recanalisation in patients with cerebral venous thrombosis under anticoagulation therapy. J Neurol Neurosurg Psychiatry. 2016;87:247-51.

12. Putaala J, Hiltunen S, Salonen O, Kaste M, Tatlisumak T. Recanalization and its correlation to outcome after cerebral venous thrombosis. J Neurol Sci. $2010 ; 292: 11-15$.

13. M. Strupp, M. Covi, K. Seelos, M. Dichgans, T. Brandt. Cerebral venous thrombosis: correlation between recanalization and clinical outcome - a long-term follow-up of 40 patients. 2002;249:1123-4

14. D.W. Schultz, S.M. Davis, B.M. Tress, C.J. Kilpatrick, J.O. King. Recanalisation and outcome cerebral venous thrombosis. J Clin Neurosci. 1996;3:133-8.
15. Baumgartner RW, Studer A, Arnold M, Georgiadis D. Recanalisation of cerebral venous thrombosis. J Neurol Neurosurg Psychiatry. 2003;74:459-61.

16. Dentali F, Gianni M, Crowther MA, Ageno W. Natural history of cerebral vein thrombosis: a systematic review. Blood. 2006;108:1129-34.

17. Güldiken B, Özkan H, Kabayel L. Mean Platelet Volume and Peripheral Blood Count Response in Acute Ischemic Stroke. Balkan Med J 2008;2:130-5.

18. Nena E, Papanas N, Steiropoulos P, Zikidou P, Zarogoulidis P, Pita E, Constantinidis TC, Maltezos E, Mikhailidis DP, Bouros D. Mean Platelet Volume and Platelet Distribution Width in non-diabetic subjects with obstructive sleep apnoea syndrome: new indices of severity? Platelets 2012;23:447-54.

19. Greisenegger S, Endler G, Hsieh K, Tentschert S, Mannhalter C, Lalouschek W. Is elevated mean platelet volume as sociated with a worse outcome in patients with acute ischemic cerebrovascular events? Stroke 2004;35:1688-1691.

20. Chu SG, Becker RC, Berger PB, Bhatt DL, Eikelboom JW, Konkle B, Mohler ER, Reilly MP, Berger JS. Mean platelet volume as a predictor of cardiovascular risk: A systematic review and metaanalysis. J Thromb Haemost. 2010;8:148-56.

21. Kamisli O, Kamisli S, Kablan Y, et al. The Prognostic Value of an Increased Mean Platelet Volume and Platelet Distribution Width in the Early Phase of Cerebral Venous Sinus Thrombosis. Clinical and Applied Thrombosis/Hemostasis 2013;19:29-32.

22. Braekkan SK, Mathiesen EB, Njølstad I, Wilsgaard T, Størmer J, Hansen JB. Mean platelet volume is a risk factor for venous thromboembolism: The TromsøStudy, Tromsø, Norway. J Thromb Haemost. 2010;8:157-62.

23. Kostrubiec M, Łabyk A, Pedowska-Włoszek J, HrynkiewiczSzymańska A, Pacho S, Jankowski K, Lichodziejewska B, Pruszczyk P. Mean platelet volume predicts early death in acute pulmonary embolism. Heart 2010;96:460-5.

24. Qiu Z, Sang H, Dai Q, Xu G. Endovascular treatments for cerebral venous sinus thrombosis. J Thromb Thrombolysis 2015;40:353-62.

25. Karadas S, Milanlioglu A, Gönüllü H, Sayin R, Aydin M. N. Cerebral venous sinus thrombosis presentation in emergency department in Van, Turkey. J. Pak. Med. Assoc. 2014;64:370-

26. Bousser M-G, Ferro JM. Cerebral venous thrombosis: an update. Lancet Neurol 2007;6:162-70.

27. Gunes H. N, Cokal B. G, Guler S. K, Yoldas T. K, Malkan U. Y, Demircan C. S, et al. Clinical associations, biological risk factors and outcomes of cerebral venous sinus thrombosis. J. Int. Med. Res. 2016;44:1454-61.

28. Bousser MG, Crassard I. Cerebral venous thrombosis, pregnancy and oral contraceptives. Thromb Res 2012;130:1922.

29. Masuhr F, Mehraein S, Einhaupl K. Cerebral venous and sinus thrombosis. J Neurol. 2004; 251:11-23.

30. Stolz E, Trittmacher S, Rahimi A, Gerriets T, Röttger C, Siekmann R, Kaps M. Influence of recanalization on outcome in dural sinus thrombosis: a prospective study. Stroke. 2004;35:544-7.

31. Gazioglu S, Eyuboglu I, Yildirim A, Aydin CO, Alioglu Z. Cerebral venous sinus Thrombosis: Clinical Features, LongTerm outcome and recanalization. J Clin Neurosci. 2017;45:248-51.

32. Ferro JM, Canhão P, Stam J, Bousser MG, Barinagarrementeria F; ISCVT Investigators. Prognosis of cerebral vein and dural sinus thrombosis: results of the International Study on Cerebral Vein and Dural Sinus Thrombosis (ISCVT). Stroke. 2004 Mar;35(3):664-70.

33. Krajíčková D, Klzo L, Krajina A, Vyšata O, Herzig R, Vališ M. Cerebral Venous Sinus Thrombosis: Clinical Characteristics and Factors Influencing Clinical Outcome. Clin Appl Thromb Hemost. 2016 Oct;22(7):665-72.

34. Lo'pez JA, Chen J. Pathophysiology of venous thrombosis. Thromb Res 2009;123:30-4.

35. Kalkan, A, Memetoğlu ME, Bilir Ö, Ersunan G, Kutlu R, Tutar N. Is Increased Mean Platelet Volume a Risk Factor in 
Patients with Acute Deep Vein Thrombosis? Tr J Emerg Med 2012;12:82-86.

36. Mathur, A, Robinson MS, Cotton J, Martin JF, Erusalimsky JD. Platelet reactivity in acute coronary syndromes: evidence for differences in platelet behaviour between unstable angina and myocardial infarction. Thromb Haemost 2001;85:989-94.

37. Demirtunc, R, Duman, D, Basar, M, Bilgi, M, Teomete, M Garip, T. The relationship between glycemic control and platelet activity in type 2 diabetes mellitus. J Diabetes Complications 2009;23:89-94.

38. Bolayır, A, Gökçe, SF. The role of mean platelet volume, platelet distribution width and platelet/lymphocyte ratio in development of cerebral venous thrombosis. Cumhuriyet Medical Journal 2017; 39: 683-91.

http://edergi.cbu.edu.tr/ojs/index.php/cbusbed isimli yazarın CBU-SBED başlıklı eseri bu Creative Commons Alınt1-Gayriticari4.0 Uluslararas1 Lisansı ile lisanslanmıştır.

(c) (1) (9) 